\title{
Portfolio Analysis of Investments in Risk Management
}

\author{
D.S.Hooda ${ }^{1}$ and M. Stehlík ${ }^{2, *}$ \\ ${ }^{1}$ Jaypee University of Engineering \& Technology, A.B. Road, Raghogarh-473226 Distt. Guna-M.P, India \\ ${ }^{2}$ Department of Applied Statistics, Johannes Kepler University, Freistädter Straße 315, 2. Stock A-4040 Linz a. D. Linz, \\ Austria
}

\begin{abstract}
In many practical investment situations the amount of available memory on stock data is extremely huge. Thus many investors are attracted to base their decisions on the information "currently available in their minds" (see [1, 2]). In the present paper various risk measurement models having application in the investment management are discussed. First we explain the concept of mean variance efficient frontier and Markowitz's model to find all efficient portfolios that maximize the expected returns and minimize the risk. Markovian risk measures are also mentioned. Some measures of portfolio analysis based on entropy mean-variance frontier are studied. Risk aversion index and Pareto-optimal sharing of risk are explained. In view of these facts it is very interesting to study how the investor should make investments so that his total expected return is maximized and the risk of losing his capital is minimized. A maximum entropy model in risk sharing is proposed and applied to some problems.
\end{abstract}

Keywords: Portfolio, Markowitz's model, Mean-Variance, Entropy.

\section{INTRODUCTION}

Every investor wants to maximize his profits by selecting proper strategy for investment. There are investments like government and bank securities, real estate, mutual funds and blue chips stocks which have low return but are relatively safe because of a proven record of non-volatility in price fluctuations. On the other hand, there are investments which bring high returns, but may be prone to a great deal of risk and the investor makes loss in case the investment goes sour. To overcome the above mentioned problem the investor should invest his funds in a spread of low and high risk securities in such a way that the total expected return for all his investments is maximized and at the same time the risk of losing his capital is minimized. Since the various outcomes as well as the probabilities of these outcomes and the return on a unit amount invested in each security are known, therefore, there is not much difficulty in maximizing the expected return. However, the main problem is to overcome risk factor. The earliest measure proposed regarding risk factor was variance of the returns on all investments in the portfolio and was based on the argument that risk increases with variance [3] gave the concept of mean-variance efficient frontier and this enabled him to find all the efficient portfolios which maximize the expected returns and minimize the variance.

Also other standard models of portfolio selection under parameter uncertainty are typically based on the assumption that investors learn about the true data generating process of asset returns using all available information. This assumption requires investors to have up to date databases of extremely large size. However, [2] argued that many investors do not

*Address correspondence to this author at the Department of Applied Statistics, Johannes Kepler University, Freistädter Straße 315, 2. Stock A-4040 Linz a. D. Linz, Austria; Tel: +43 7322468 5881; Fax: +43 7322468 9846; E-mail: Milan.Stehlik@jku.at use databases as econometricians, but make decisions based on the information currently available "in their minds". In line with this argument [1] presents a model where individuals exert mental effort to estimate the parameters of an economic model, by retrieving observations from a stock of memories.

In our paper we would like to provide approaches how to reduce the "dimensionality of the problem" of finding the optimal investment, which is typically not uniquely defined. The main principle we use is the information theory approach [4]. Made a brief account of application of entropy optimization principles in minimizing risk in portfolio analysis [5] have applied these principles in characterizing crop area distributions for optimal yield. In this paper we make a study of various risk measure models and discuss their utilities in finance management. The paper is organized as follows.

In section 2 we discuss the Markowitz Mean-VarianceEfficient Frontier and interpret it in the context of maxEnt optimization. In section 3 we discuss the Maximum Entropy Mean-Variance Frontier. In section 4 we introduce the concept of Markovian risk measure. In section 5 we discuss the Risk Aversion Index. In section 6 we discuss the ParetoOptimal Sharing of Risks. Finally in section 7 the Maximum Entropy principle in Risk Sharing is discussed.

\section{MARKOWITZ MEAN-VARIANCE-EFFICIENT FRONTIER}

Let $\Pi_{j}$ be the probability of $j$ th outcome for $j=1,2, \ldots, m$ and $r_{i j}$ be the return on ith security for $\mathrm{i}=1,2, \ldots \mathrm{n}$, when $\mathrm{jth}$ outcome occurs. Then the expected return on the ith security is

$\overline{\mathrm{r}_{\mathrm{i}}}=\sum_{j=1}^{m} \Pi_{\mathrm{j}} \mathrm{r}_{\mathrm{ij}}, \mathrm{i}=1,2, \ldots, \mathrm{n}$ 
Variance and covariance of returns are given by

$\sigma_{\mathrm{i}}^{2}=\sum_{j=1}^{m} \Pi_{\mathrm{j}}\left(\mathrm{r}_{\mathrm{ij}}-\overline{\mathrm{r}}_{\mathrm{i}}\right)^{2}, \mathrm{i}=1,2, \ldots, \mathrm{n}$

and

$\rho_{\mathrm{ik}} \sigma_{\mathrm{i}} \sigma_{\mathrm{k}}=\sum_{j=1}^{m} \Pi_{\mathrm{j}}\left(\mathrm{r}_{\mathrm{ij}}-\overline{\mathrm{r}_{\mathrm{i}}}\right)\left(\mathrm{r}_{\mathrm{kj}}-\overline{\mathrm{r}_{\mathrm{k}}}\right), \mathrm{i}, \mathrm{k}=1,2, \ldots, \mathrm{n} ; \mathrm{i} \neq \mathrm{k}$,

where $\rho_{\mathrm{ik}}$ is correlation coefficient. A person decides to invest proportions $\mathrm{x}_{1}, \mathrm{x}_{2}, \ldots, \mathrm{x}_{\mathrm{n}}$ of his capitals in $\mathrm{n}$ securities. If $\mathrm{x}_{\mathrm{i}} \geq 0$ for all $\mathrm{i}$ and $\sum_{i=1}^{n} \mathrm{x}_{\mathrm{i}}=1$, then the mean and variance of the expected returns are given by

$\mathrm{E}=\overline{\mathrm{R}}=\sum_{i=1}^{n} \mathrm{x}_{\mathrm{i}} \overline{\mathrm{r}}_{\mathrm{i}}$

and

$\mathrm{V}=\sum_{i}^{n} \mathrm{x}_{\mathrm{i}}^{2} \sigma_{\mathrm{i}}^{2}+2 \sum_{k=1}^{n} \sum_{i<k} \mathrm{x}_{\mathrm{i}} \mathrm{x}_{\mathrm{k}} \rho_{\mathrm{ik}} \sigma_{\mathrm{i}} \sigma_{\mathrm{k}}$

Markowitz [3] suggested that $x_{1}, x_{2}, \ldots, x_{n}$ be chosen to maximize $\mathrm{E}$ and to minimize $\mathrm{V}$ or alternatively, to minimize $\mathrm{V}$ keeping $\mathrm{E}$ at a fixed value.

Now

$\mathrm{V}=\sum_{j=1}^{m} \Pi_{\mathrm{j}}\left(\mathrm{R}_{\mathrm{j}}-\overline{\mathrm{R}}\right)^{2}$

where $\mathrm{R}_{\mathrm{j}}=\sum_{i=1}^{n} \mathrm{x}_{\mathrm{i}} \mathrm{r}_{\mathrm{ij}}$ i.e. $\mathrm{R}_{\mathrm{j}}$ is the return on investment when jth outcome arises, and $\bar{R}$ is the mean return on investment.

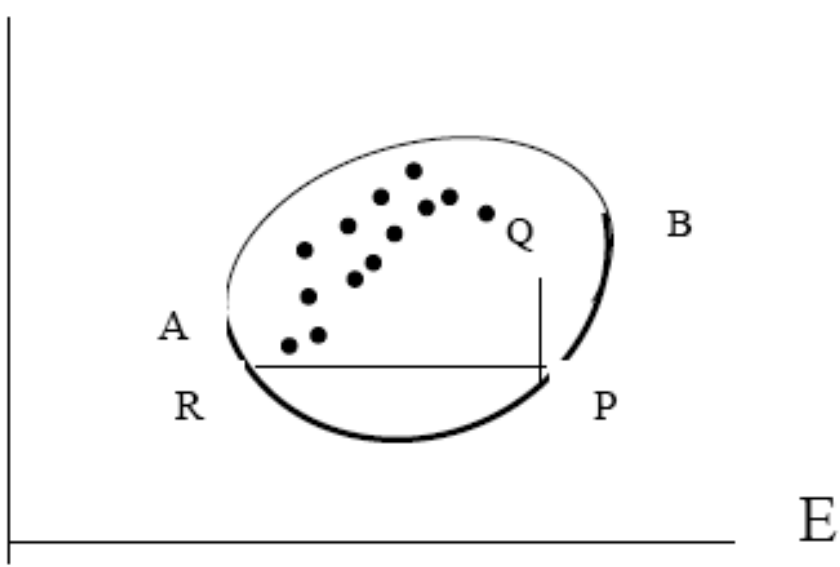

Fig. (1). Source: made by ourselves

Corresponding to each vector $\left(\mathrm{x}_{1}, \mathrm{x}_{2}, \ldots, \mathrm{x}_{\mathrm{n}}\right)$, there are certain values of $\mathrm{E}$ and $\mathrm{V}$, so that corresponding to each portfolio, there is unique point in the E-V plane. In the Fig. (1) the arc $\mathrm{AB}$ gives the lower boundary at the convex region obtained. In this figure it can be easily seen that the portfolio corresponding to $\mathrm{P}$ is more efficient than the portfolio corresponding to $\mathrm{Q}$ because the mean return for both is the same, but variance for $\mathrm{Q}$ is greater than that of $\mathrm{P}$. Similarly the portfolio corresponding to $\mathrm{P}$ is also more efficient than the portfolio corresponding to $\mathrm{R}$, because in both cases the variance is equal, while the mean return for $\mathrm{P}$ is higher than that for $\mathrm{R}$. Thus the portfolio corresponding to any other point on the arc $\mathrm{AB}$ is more efficient than a portfolio corresponding to any other point inside the convex region. However, portfolios corresponding to different points on the arc $\mathrm{AB}$ are not comparable, because in one portfolio the mean return may be higher, while for the other variance may be smaller. The portfolio corresponding to points of the arc $\mathrm{AB}$ are called mean-variance efficient frontier.

If a person chooses the portfolio corresponding to $\mathrm{B}$ it gives the highest possible value for $\mathrm{E}$, but $\mathrm{V}$ is large at $\mathrm{B}$. This means the person is interested in making his expected income large and does not mind whether variance becomes large and his risk is increased. Such persons who do not worry about risks are also known as risk-prone. On the other hand, persons who want to avoid risk and are cautious are called risk-averse and they will choose points near A. Thus the choice of point on the arc $\mathrm{AB}$ depends on the attitude to the risk of the investor concerned.

Markowitz's mean-variance (MV) efficient portfolio selection is one of the most widely used approaches in solving portfolio diversification problem. However, contrary to the notion of diversification, MV approach often leads to portfolio highly concentrated on a few assets. Also, this method leads to negative values for some portfolio weights (short sales), while in practice most asset managers are not allowed to sell short. On the other hand entropy is a well accepted measure of diversity and recently, some works analyzing the problem of portfolio diversification/optimization using information theory concepts have been done (see Bera and Park [6] and Luo [7]). In the next section of paper we discuss the maximum entropy mean variance frontier.

\section{MAXIMUM ENTROPY MEAN-VARIANCE FRONTIER}

One of the investor's objective is to diversify his portfolio so that out of all points on the mean-variance efficient frontier, he chooses that portfolio for which his investments in different stocks are chosen so as to make $R_{1}, R_{2}, \ldots, R_{m}$ as equal as possible among themselves. Any departure of $R_{1}$, $R_{2}, . ., R_{m}$ from equality is considered a measure of risk which can be minimized if we choose $x_{1}, x_{2}, \ldots, x_{n}$ so as to maximize the entropy measure

$$
-\sum_{j=1}^{n} \frac{R_{j}}{\sum_{j=1}^{m} R_{J}} \log \frac{R_{j}}{\sum_{j=1}^{m} R_{J}}
$$

Since (3.1) does not include $\Pi_{\mathrm{j}}$ 's, therefore, we can modify the principle to say that $\Pi_{\mathrm{j}} \mathrm{R}_{\mathrm{j}}$ 's should be as equal as possible i.e. the entropy of the probability distribution $\frac{\Pi_{j} R_{J}}{\bar{R}}$ should be as large as possible. For this we maximize

$-\sum_{j=1}^{n} \frac{\Pi_{j} R_{j}}{\bar{R}} \log \frac{\Pi_{J} R_{J}}{\bar{R}}$ 
subject to

$$
\sum_{j=1}^{m} \Pi_{j} R_{J}=\bar{R}
$$

Applying Lagrange's method of multipliers, we get

$$
\Pi_{j} R_{j}=\frac{\bar{R}}{m}
$$

Thus according to our first principle $\mathrm{R}_{\mathrm{J}}=\overline{\mathrm{R}}$, while according to second principle

$\mathrm{R}_{\mathrm{j}}=\frac{1}{\Pi_{j}} \frac{\bar{R}}{m}$

If $\Pi_{j}=1 / \mathrm{m}$ i.e. if the outcomes are equally likely, the two principles give the same results.

Again since we want $R_{j}$ 's to be as equal as possible we want the probability distribution

$\mathrm{P}_{\mathrm{j}}=\frac{\Pi_{j} R_{j}}{\bar{R}}$

to be as close to the probability distribution $\Pi_{\mathrm{j}}$ as possible. So we chose $x_{1}, x_{2}, \ldots, x_{n}$ to minimize either $D\left(P_{j}, \Pi_{j}\right)$ or $\mathrm{D}\left(\Pi_{\mathrm{j}}, \mathrm{P}_{\mathrm{j}}\right)$, as defined in (3.5) below.

If we use Kullback and Leibler [8]'s measure, it implies that $\sum_{j=1}^{m} \Pi_{j} R_{j} \log \mathrm{R}_{\mathrm{j}}$ should be as small as possible. This is the third principle.

Next to minimize $\mathrm{D}\left(\Pi_{\mathrm{j}}, \mathrm{P}_{\mathrm{j}}\right)$ we again apply KullbackLeibler's measure and get

$$
\sum_{j=1}^{m} \Pi_{j} \log \frac{\Pi_{j}}{P_{j}} \text { or } \sum_{j=1}^{m} \Pi_{j} \log \Pi_{j} R_{j}
$$

should be as small as possible, which is fourth principle. We can also use Harvda and Charvat [9]'s measure of directed divergence or cross-entropy. In that case we have to minimize

$$
\frac{1}{\alpha-1}\left(\sum_{j=1}^{m} P_{j}^{\alpha} \Pi_{j}^{1-\alpha}-1\right) \text { or } \frac{1}{\alpha-1}\left(\sum_{j=1}^{m} \Pi_{j}^{\alpha} P_{j}^{1-\alpha}-1\right)
$$

Thus according to $5^{\text {th }}$ and $6^{\text {th }}$ principle, we choose $x_{1}, x_{2}, \ldots$, $\mathrm{x}_{\mathrm{n}}$ to minimize respectively

$\frac{1}{\alpha-1} E\left(R^{1-\alpha}-1\right)$ or $\frac{1}{\alpha-1} E\left(R^{\alpha}-1\right)$, where $\mathrm{R}=\frac{\Pi_{j}}{P_{j}}$.

\section{MARKOVIAN RISK MEASURE}

Particularly, one can be interested in the risk measure based on the Markov inequality,

so called Markovian risk measure (see [10]). Markov inequality can be generalized as follows:

Let $X$ be a random variable, $a \in R$. Let $\Phi(x, y)$ be any Lebesgue measurable bivariate function and $v(x)$ any non- negative and non-decreasing function such that $E[v(X)]<\infty$ and $E[\Phi(X, y) v(X)]<\infty$ for all relevant $y$. Then

$P\{X \geq a\} \leq \frac{E[\Phi(X, a) v(X)]}{E[v(X)]}$.

Supposing $\quad X \geq 0$ with probability 1, $a \geq 0$, $\Phi(x, y)=x^{r} / y^{r}$ and $v=1$ in Markov inequality, one gets Markov inequality as a special case of (4.2). The risk measure $\pi$ is a mapping from the set of risk (random) variables to the set of real numbers. It follows we put $X=S$, where $S$ is a risk variable. In view of (4.2) it is not difficult to prove that, under certain conditions and for some $\alpha, 0 \leq \alpha \leq 1$, there exists a minimal value $\pi_{M}$ such that

$P\left[S>\pi_{M}\right] \leq E\left[\Phi\left(S, \pi_{M}\right) v(S)\right] / E[v(S)] \leq \alpha \leq 1$.

which is the solution of the equation

$E\left[\Phi\left(S, \pi_{M}\right) v(S)\right] / E[v(S)]=\alpha$

and is called a Markovian risk measure of the risk variable $S$ at level $\alpha$.

When $\alpha=1$, the equation

$E\left[\Phi\left(S, \pi_{M}\right) v(S)\right] / E[v(S)]=1$.

which is called the unifying equation. Many well-known insurance premium principles and corresponding risk measures follow from (4.4) as special cases i.e. the mean value principle, the zero-utility premium principle and the Swiss premium calculation principle (see also [10]). For dividend strategies of insurance companies see [11].

\section{RISK AVERSION INDEX}

Let us consider a lottery in which the returns are $\mathrm{x}_{1}$, $\mathrm{x}_{2}, \ldots, \mathrm{x}_{\mathrm{n}}$ with probabilities $\mathrm{p}_{1}, \mathrm{p}_{2}, \ldots, \mathrm{p}_{\mathrm{n}}$ so that mean monetary return is

$\overline{\mathrm{x}}=\sum_{i=1}^{n} p_{i} x_{i}$

It may be noted that the utility, $\mathrm{u}(\mathrm{x})$, of an amount $\mathrm{x}$ is not always proportional to $\mathrm{x}$. If the monetary value is doubled, for some persons the utility increases, but it is less than double of the previous one. Such persons are also called riskaverse and those for which the utility is more than doubled will be called risk-prone. Thus the attitude to risk of every person is characterized by $\mathrm{u}(\mathrm{x})$. For risk-averse persons, $\mathrm{u}(\mathrm{x})$ increases at a decreasing rate i.e. $\mathrm{u}^{\prime \prime}(\mathrm{x})<0$ or $\mathrm{u}(\mathrm{x})$ is concave function, while for risk-prone persons $\mathrm{u}^{\prime \prime}(\mathrm{x})>0$ and $\mathrm{u}(\mathrm{x})$ is a convex function and for risk-neutral persons $\mathrm{u}^{\prime \prime}(\mathrm{x})=0$.

Pratt [12] and Arrow [13] defined a risk-aversion index (RAI) as

$\mathrm{RAI}=-\frac{u^{\prime \prime}(x)}{u^{\prime}(x)}$ 
It can be easily verified that if $\mathrm{u}(\mathrm{x})=\log \mathrm{x}$, then $\mathrm{RAI}=$ $1 / x>0$ and if $u(x)=e^{x}$, then RAI $=-1<0$ and RAI $=0$ in case $\mathrm{u}(\mathrm{x})=\mathrm{x}$.

Next, we explain how the expression (5.2) can be obtained by two different methods. We define $\overline{\mathrm{x}}=\sum_{i=1}^{n} p_{i} x_{i}$ as certain monetary equivalent (CME) and also define $\tilde{x}$ by

$\mathrm{u}(\mathrm{X}+\tilde{x})=\sum_{i=1}^{n} p_{i} u\left(\mathrm{X}+\mathrm{x}_{\mathrm{i}}\right)$,

where $\mathrm{X}$ is the positive initial capital. (5.3) can be written as

$\mathrm{u}(\mathrm{X}+\tilde{x}+\overline{\mathrm{x}}-\overline{\mathrm{x}})=\sum_{i=1}^{n} p_{i} u\left(\mathrm{X}+\overline{\mathrm{x}}+\mathrm{x}_{\mathrm{i}}-\overline{\mathrm{x}}\right)$

or

$$
\begin{aligned}
& \mathrm{u}(\mathrm{X}+\overline{\mathrm{x}})+(\tilde{x}-\overline{\mathrm{x}}) \mathrm{u}^{\prime}(\mathrm{X}+\overline{\mathrm{x}})+\frac{(\tilde{x}-\bar{x})^{2}}{2 !} u^{\prime \prime}(X+\bar{x})+\ldots \\
& =\mathrm{u}(\mathrm{X}+\overline{\mathrm{x}})+ \\
& \sum_{i=1}^{n} p_{i}\left(x_{i}-\bar{x}\right) u^{\prime}(X+\bar{x})+\sum_{i=1}^{n} p_{i} \frac{\left(x_{i}-\bar{x}\right)^{2}}{2 !} u^{\prime \prime}(X+\bar{x})+\ldots
\end{aligned}
$$

Neglecting $(\tilde{x}-\bar{x})^{3}$ and higher orders in this Taylor series expansion, we have

$\overline{\mathrm{x}}-\tilde{x}=-\frac{1}{2} \frac{u^{\prime \prime}(X+\bar{x}) \sigma_{x}^{2}}{u^{\prime}(X+\bar{x})}=\frac{1}{2}(R A I) \sigma_{x}^{2}$

Thus CME exceeds $\tilde{\mathrm{X}}$ by an amount proportional to RAI and this arises due to the attitude to risk of the investor. The concept of RAI can be generalized for $\mathrm{u}(\mathrm{x}, \mathrm{y})$ and we get

$\mathrm{RAI}=\mathrm{r}_{11} \sigma_{\mathrm{x}}^{2}+2 \mathrm{r}_{12} \sigma_{\mathrm{x}} \sigma_{\mathrm{y}}+\mathrm{r}_{22} \sigma_{\mathrm{y}}^{2}$,

where risk averse functions are

$\mathrm{r}_{11}=-\frac{1}{2} \frac{u_{x x}}{\left(u_{x}^{2}+u_{y}^{2}\right)^{1 / 2}}, r_{12}=-\frac{u_{x y}}{\left(u_{x}^{2}+u_{y}^{2}\right)^{1 / 2}}, r_{22}=-\frac{1}{2} \frac{u_{y y}}{\left(u_{x}^{2}+u_{y}^{2}\right)^{1 / 2}}$.

This can be further generalized for $\mathrm{u}\left(\mathrm{x}_{1}, \mathrm{x}_{2}, \ldots, \mathrm{x}_{\mathrm{n}}\right)$ to get

$\mathrm{RAI}=-\frac{1}{2}\left(\sum_{i=1}^{n} r_{i i} \sigma_{i}^{2}+2 \sum_{i=1}^{n} \sum_{j=1}^{m} r_{i j} \sigma_{i} \sigma_{j}\right)$,

where

$\mathrm{r}_{\mathrm{ij}}=\left(\frac{\partial^{2} u}{\partial x_{i} \partial x_{j}}\right)\left(\sum_{i=1}^{n}\left(\frac{\partial u}{\partial x_{i}}\right)^{2}\right)^{-1 / 2}$

If risk aversion index for two variables is 0 , then

$\mathrm{u}_{\mathrm{xx}} \sigma_{\mathrm{x}}^{2}+2 \mathrm{u}_{\mathrm{xy}} \sigma_{\mathrm{x}} \sigma_{\mathrm{y}}+\mathrm{u}_{\mathrm{yy}} \sigma_{\mathrm{y}}{ }^{2}=0$,

which is an elliptic partial differential equation of second order.

\section{PARETO-OPTIMAL SHARING OF RISKS}

A number $m$ of persons agree to share risks in a business on basis of optimal sharing of risks and profits in such a manner that no individual can increase his expected utility without decreasing the expected utilities of others.

Let a risk have $n$ possible states $s_{1}, s_{2}, \ldots, s_{n}$ with payments $\mathrm{x}_{1}, \mathrm{x}_{2}, \ldots, \mathrm{x}_{\mathrm{n}}$ and with probabilities $\mathrm{p}_{1}, \mathrm{p}_{2}, \ldots, \mathrm{p}_{\mathrm{n}}$. Let payments be partitioned among $\mathrm{m}$ individuals whose utility functions are

$\mathrm{u}_{1}, \mathrm{u}_{2}, \ldots, \mathrm{u}_{\mathrm{m}}$. Let $\mathrm{x}_{\mathrm{ij}}$ be the payment of $\mathrm{jth}$ individual in case of ith outcome, then the expected utility of this partitioned risk is given by

$\overline{\mathrm{u}}_{\mathrm{j}}=\sum_{i=1}^{n} p_{i} u_{j} x_{i j}, \mathrm{j}=1,2, \ldots, \mathrm{m}$, where $\sum_{j=1}^{m} x_{i j}=\mathrm{x}_{\mathrm{i}}$.

We can plot the $\mathrm{m}$ expected utilities in $\mathrm{m}$ dimensional space. If the $m$ expected utilities are negative, then no partition is acceptable because $(0,0, \ldots, 0)$ will be preferred by all. In case all $\mathrm{u}_{\mathrm{i}}$ 's are positive, we maximize

$\lambda_{\mathrm{i}} \overline{\mathrm{u}}_{\mathrm{i}}+\lambda_{2} \overline{\mathrm{u}}_{2}+\ldots . \lambda_{\mathrm{m}} \overline{\mathrm{u}}_{\mathrm{m}}$

subject to $\sum_{j=1}^{m} \lambda_{j}=1, \lambda_{j}>0$. Thus we get a linear hyperplane

$\lambda_{1} \overline{\mathrm{u}}_{1}+\lambda_{2} \overline{\mathrm{u}}_{2}+\ldots+\lambda_{\mathrm{m}} \overline{\mathrm{u}}_{\mathrm{m}}=\mathrm{k}\left(\lambda_{1}, \lambda_{2}, \ldots, \lambda_{\mathrm{m}}\right)$

The envelope of this hyperplane gives the equation of the Pareto optimal hyperplane. All points of this hyper-surface are accepted but which point is chosen depends on the relative bargaining power of the partner or they can choose the point of intersection with the line

$\overline{\mathrm{u}}_{1}=\overline{\mathrm{u}}_{2}=\ldots=\overline{\mathrm{u}}_{\mathrm{m}}$. Thus this equitable Pareto optimal sharing can be obtained instead of individual. We can have groups fighting for increasing their social, political or economic utilities and arriving at Pareto Optimal Equilibria. When these equilibria are disturbed, new Pareto optimal equilibrium positions have to be obtained.

\section{MAXIMUM ENTROPY PRINCIPLE IN RISK SHARING}

The Pareto optimal boundary gives infinity of solutions and we need one more criterion to get a unique solution. This is possible by considering that payments are divided as uniformly as possible subject to other constraints Kapur [14]. For this we maximize the following measure of entropy as suggested by Kapur [14]:

$$
\begin{aligned}
& \mathrm{H}^{*}=-\sum_{i=1}^{n} p_{i} \sum_{j=1}^{m} \frac{x_{i j}}{x_{i}} \log \frac{x_{i j}}{x_{i}}=-\sum_{i=1}^{n} \frac{p_{i}}{x_{i}} \sum_{j=1}^{m} x_{i j} \log x_{i j}+\sum_{i=1}^{n} p_{i} \log x_{i} \\
& =-\sum_{i=1}^{n} \frac{p_{i}}{x_{i}} \sum_{j=1}^{m} x_{i j} \log \mathrm{x}_{\mathrm{ij}}+\text { constant. }
\end{aligned}
$$

Thus out of all Pareto Optimal solutions we choose that one which maximizes $\mathrm{H}^{*}$.

Raiffa [15] has shown that the Pareto Optimal solution is obtained by maximizing 


$$
\begin{aligned}
& \sum_{j=1}^{m} \lambda_{j} \bar{u}_{j}=\sum_{j=1}^{m} \lambda_{j} \sum_{i=1}^{n} p_{i} u_{j}\left(x_{i j}\right) \\
& =\sum_{i=1}^{n} p_{i} \sum_{j=1}^{m} \lambda_{j} u_{j}\left(x_{i j}\right)
\end{aligned}
$$

subject to

$$
\sum_{j=1}^{m} x_{i j}=x_{i}, \sum_{j=1}^{m} \lambda_{j}=1
$$

This will determine $x_{i j}$ in term of $\lambda_{1}, \lambda_{2}, \ldots, \lambda_{m}$.

Example 1. Special Case of Exponential Utility Function Let us consider

$\mathrm{u}_{\mathrm{j}}(\mathrm{x})=1-e^{\frac{-x}{c_{j}}}, \mathrm{j}=1,2, \ldots, \mathrm{m}$

We maximize $\sum_{i=1}^{n} p_{i} \lambda_{j}\left(1-e^{\frac{-x_{i j}}{c_{j}}}\right)$ subject to

$\sum_{j=1}^{m} x_{i j}=x_{i}, \sum_{j=1}^{m} \lambda_{j}=1$

Following Lagrange's method of multiplier, we get

$\frac{x_{i j}}{c_{j}}=\frac{x_{i}}{c}-\sum_{j=1}^{m} \frac{c_{j}}{c} \log \frac{\lambda_{j}}{c_{j}}+\log \frac{\lambda_{j}}{c_{j}}$,

where $\mathrm{c}=\sum_{j=1}^{m} c_{j}$. Substituting in (6.1) and differentiating w.r.t. $\lambda_{\mathrm{k}}$

$\frac{\partial H^{*}}{\partial \lambda_{k}}=\sum_{i=1}^{n} p_{i} \sum_{j=1}^{m} \log \left(1+x_{i j}\right)\left[\frac{c_{k}}{c} \frac{1}{\lambda_{k}}+\frac{1}{\lambda_{j}}+\delta_{j k}\right]$

$=\sum_{i=1}^{n} p_{i} \frac{c_{k}}{\lambda_{k}}\left[\sum_{j=1}^{m}\left(1+\log x_{i j} \frac{c_{j}}{c}-\log \left(1+x_{i k}\right)\right]\right.$

Since $\sum_{k=1}^{m} \lambda_{k}=1$, this gives

$\frac{c_{1}\left(A-B_{1}\right)}{\lambda_{1}}=\frac{c_{2}\left(A-B_{2}\right)}{\lambda_{2}}=\ldots=\frac{c_{n}\left(A-B_{n}\right)}{\lambda_{n}}=\frac{C A-\sum_{j=1}^{m} B_{J} C_{J}}{1}$

where

$\mathrm{A}=\sum_{i=1}^{m} p_{i} \sum_{j=1}^{m} \log \left(1+x_{i j}\right) \frac{c_{j}}{c}$ and $B_{k}=\sum_{i=1}^{n} p_{i} \log \left(1+x_{i k}\right)$

Using (7.4), (7.5), (7.7) and (7.8) we can solve for $\mathrm{x}_{\mathrm{ij}}$ 's and $\lambda_{\mathrm{j}}$ 's.

Example 2. Estimation and testing for the Utility function
Let us assume the exponential utility function $u_{j}(x)=1$ $\exp \left(-x / c_{j}\right) ; j=1 ; 2 ; \ldots ; m:$ In economics exponential utility refers to a specific form of the utility function, used in many contexts because of its convenience when uncertainty is present. Formally, exponential utility is given by the assumption that $x$ and $c_{j}$ are constants. For such a testing we employ an efficient LR test of scale-homogeneity hypothesis

$H_{0}: c_{1}=::=c_{N}$

for i.i.d. observations from exponential utility function versus general (nonH0), or more sophisticated finite scale mixture alternatives ([16]).

Under the homogeneity we justify the maximum likelihood estimator and provide the exact LR test of the scale parameter value, i.e.

$H_{0}: c=c_{0}$ versus $H_{1}: c \neq c_{0}$ :

The tests of homogeneity and scale can be choosen to be asymptotically optimal in the Bahadur sense when the underlying distribution is exponential, (see Rublík [17, 18] and Stehlík 16]). For estimation of general utility function see Stehlik [19].

\section{ACKNOWLEDGEMENTS}

We acknowledged our gratitude to the reviewers for their constructive comments. The present paper is the output of collaborative research undertaken by the authors and they are thankful to Professor Werner G. Müller, IFAS, Johannes Kepler University in Linz for his support and encouragement.

\section{REFERENCES}

[1] D. Nocetti, "A model of mental effort and endogenous estimation risk." Econ. Bull., vol. 4, no. 14 pp. 1-10, 2005.

[2] D. Nocetti, "Portfolio Selection with endogenous estimation risk." Econ. Bull., vol. 7, no. 6, pp. 1-9, 2006.

[3] H. M. Markowitz, Portfolio Selection; Efficient Diversification of Investments, John Wiley: New York, 1959.

[4] J. N. Kapur and H. K. Kesavan, Entropy Optimization Principles with Applications, Academic Press: INC, 1992.

[5] D. S. Hooda and J. N. Kapur, "Crop area distributions for optimal yield”, Opsearch., vol. 38, pp. 407-418, 2001.

[6] A. K. Bera and S, Y. Park, "Optimal portfolio diversification Using maximum entropy", Econ. Rev., vol. 27, pp. 484-512, 2008.

[7] Y. Luo, "Rational inattention, long-run consumption risk, and portfolio choice", Rev. Econ. Dyn., vol. 13 no. 4, pp. 843-860, 2010.

[8] S. Kullback and R. A. Leibler, "On information and sufficiency", Ann. Math. Stat. vol. 22, pp. 79-86, 1951.

[9] J. Harvda and F. Charvat, "Quantification method of classification processes-concept of $\alpha$-entropy”, Kybernetika, vol. 3, pp. 30-35, (1967).

[10] M. J. Goovaerts, R. Kaas, J. Dhaene and Q. A. Tang, "Unified approach to generate risk measures". Astin. Bull., vol. 32, no. 2, pp. 173-191, 2003

[11] R. Potocký. "On a dividend strategy of insurance companies" EKONOMIE. A. M. vol. 11 no. 4, pp. 103-109, 2008.

[12] J. W. Pratt, "Risk aversion in the small and in the large", Econometrics, vol. 32, pp. 122-136, 1964.

[13] K. J. Arrow, "Essays on the theory of risk bearing", Markhan Publishers: Chicago, 1971.

[14] J. N. Kapur, Maximum Entropy Models in Science and Engineering, Wiley Eastern Limited: N. Delhi, 1989.

[15] H. Raiffa, Decision Analysis: Introductory Readings on Choices Under Uncertainty, McGraw Hill: USA, 1997.

[16] M. Stehlík and W. Wagner, "Exact likelihood ratio testing for homogeneity of exponential distribution", Commun. Stat. (accepted, 2010). 
[17] F. Rublík, "On optimality of the LR tests in the sense of exact slopes“, General. Case. Kybernetika., vol. 25, pp. 13-25, 1989

[18] F. Rublík, "On optimality of the LR tests in the sense of exact slopes", App. Individual. Dis. Kybernetika., vol. 25, pp. 117-135, 1989.
[19] M. Stehlík, "Distributions of exact tests in the exponential family", Metrika. vol. 57, pp. 145-164, 2003.

Received: May 12, 2011

Revised: June 25, 2011

Accepted: June 28, 2011

(C) Hooda and Stehlík; Licensee Bentham Open.

This is an open access article licensed under the terms of the Creative Commons Attribution Non-Commercial License (http://creativecommons.org/licenses/by-nc/3.0/) which permits unrestricted, non-commercial use, distribution and reproduction in any medium, provided the work is properly cited. 